\title{
Immune response pattern in recurrent Plasmodium vivax malaria
}

\author{
Yury Oliveira Chaves ${ }^{1 \dagger}$, Allyson Guimarães da Costa ${ }^{2,3,4 \dagger}$, Marcelo Luís Monteiro Pereira ${ }^{5}$, \\ Marcus Vinícius Guimarães de Lacerda ${ }^{1,2,3}$, Jordana Grazziela Coelho-dos-Reis ${ }^{6}$, Olindo Assis Martins-Filho ${ }^{6}$, \\ Andréa Teixeira-Carvalho ${ }^{6}$, Adriana Malheiro ${ }^{4,7}$, Wuelton Marcelo Monteiro ${ }^{2,3}$, Patrícia Puccinelli Orlandi ${ }^{1}$, \\ Claudio Romero Farias Marinho 5 and Paulo Afonso Nogueira ${ }^{1 *}$
}

\begin{abstract}
Background: Plasmodium vivax is the causative agent of human malaria of large geographic distribution, with 35 million cases annually. In Brazil, it is the most prevalent species, being responsible by around $70 \%$ of the malaria cases.

Methods: A cross-sectional study was performed in Manaus (Amazonas, Brazil), including 36 adult patients with primary malaria, 19 with recurrent malaria, and 20 endemic controls. The ex vivo phenotypic features of circulating leukocyte subsets (CD4 ${ }^{+}$T-cells, CD8 ${ }^{+}$T-cells, NK, NKT, B, B1 and Treg cells) as well as the plasmatic cytokine profile (IL-2, IL-4, IL-6, IL-10, TNF and IFN- $\gamma$ ) were assessed, aiming at establishing patterns of immune response characteristic of primary malaria vs recurrent malaria as compared to endemic controls.

Results: The proportion of subjects with high levels of WBC was reduced in malaria patients as compared to the endemic control. Monocytes were diminished particularly in patients with primary malaria. The proportion of subjects with high levels of all lymphocyte subsets was decreased in all malaria groups, regardless their clinical status. Decreased proportion of subjects with high levels of $\mathrm{CD}^{+}$and $\mathrm{CD} 8^{+} \mathrm{T}$-cells was found especially in the group of patients with recurrent malaria. Data analysis indicated significant increase in the proportion of the subjects with high plasmatic cytokine levels in both malaria groups, characterizing a typical cytokine storm. Recurrent malaria patients displayed the highest plasmatic IL-10 levels, that correlated directly with the CD4 $4^{+} / \mathrm{CD} 8^{+} \mathrm{T}$-cells ratio and the number of malaria episodes.
\end{abstract}

Conclusion: The findings confirm that the infection by the P. vivax causes a decrease in peripheral blood lymphocyte subsets, which is intensified in the cases of "recurrent malaria". The unbalanced CD4 ${ }^{+} / \mathrm{CD} 8^{+} \mathrm{T}$-cells ratio, as well as increased IL-10 levels were correlated with the number of recurrent malaria episodes. These results suggest that the gradual remodelling of the immune response is dependent on the repeated exposure to the parasite, which involves a strict control of the immune response mediated by the $\mathrm{CD} 4^{+} / \mathrm{CD} 8^{+}$T-cell unbalance and exacerbated IL-10 secretion.

Keywords: Malaria, Recurrence, Plasmodium vivax, Interleukin-10, CD4 ${ }^{+}$T-cells, CD8 ${ }^{+}$T-cells

\section{Background}

Plasmodium vivax is widely distributed around the world, with more than 2.5 billion subjects exposed to risk

\footnotetext{
*Correspondence: paulo.nogueira@fiocruz.br

${ }^{\dagger}$ Yury Oliveira Chaves and Allyson Guimarães da Costa contributed equally to this work

${ }^{1}$ Instituto Leônidas e Maria Deane, Fundação Oswaldo Cruz (FIOCRUZ),

Manaus, AM, Brazil

Full list of author information is available at the end of the article
}

of infection. Plasmodium vivax malaria is highly prevalent in Latin America, Asian and some Pacific regions [1]. In the past, $P$. vivax was considered the causative agent of "benign malaria" and was associated with low lethality. However, after several reports of severe forms of $P$. viva $x$ malaria, this assumption has been challenged $[2,3]$. Recent studies have shown that vivax malaria can be associated with a spectrum of severe syndrome, with risk 
of death similar to that observed for Plasmodium falciparum infection [4-9].

In Brazil, the Amazon region concentrates almost all cases of $P$. vivax infections registered countrywide, with more than 300 thousand cases per year [10]. Although the Amazon region has low transmission levels as compared to other regions in sub-Saharan Africa, the most affected population in the Amazon Basin are adults and the incidence of complications has been already reported $[11,12]$.

The recurrence of $P$. vivax malaria is a phenomenon that commonly occurs within a few months after the treatment of primary infection. The recurrence is defined as the reappearance of asexual forms of the parasite in the blood, up to 6 months after post-therapeutic monitoring period [13]. Usually, relapse/recrudescence may also occur for different reasons such as resistance of the parasite to the chemotherapy used [14], therapeutic failure, non-adherence to the treatment [15] and reactivation of the hypnozoites [16]. Recurrence has been rather considered a new malaria episode occurring in endemic areas after effective therapeutic intervention [17].

Although the mechanisms underlying the recurrence of are still unknown, cases of "recurrent malaria" are usually associated with impaired clinical recovery and higher morbidity, worsening the socio-economic impact of the disease [18-20]. From the epidemiologic point of view, it is likely that the recurrence favors the maintenance and transmission of the parasite, considering the early and continual presence of sexual forms of the P. vivax [21].

Several evidences suggest that an exacerbated inflammatory response associated to a high parasitaemia is likely to aggravate the malaria symptoms [22-27]. The exacerbated activation of the host immune system, especially T-lymphocytes is the core factor to the severe malaria pathogenicity, related to the high and out of proportion levels of the pro-inflammatory cytokines, which can be observed during the erythrocytic phase of the parasite life cycle $[9,28-30]$. In general, the severity of the disease has been associated with high systemic levels of IFN- $\gamma$ and TNF [31-33]. In the P. vivax malaria, the simultaneous increase of the TNF, IFN- $\gamma$ and IL-10 has been correlated to disease progression towards a severe clinical outcome $[9,34,35]$.

Counterbalancing the exacerbated inflammatory response that induces immunopathological mechanisms [28], the host immune response develops modulatory events, especially in the lymphocytic compartment [3640]. It stands out the role of the regulatory T-cells (Treg), which may act as an important key both to the homoeostatic balance and to the control of the immunopathogenesis through the modulation of the excessive inflammatory response [41]. Treg cells are necessary to control the cellular immune response through a direct contact with the effector immune cells and by the production of regulatory cytokines including IL-10 and TGF- $\beta$ [42-44]. Furthermore, anti-inflammatory cytokines, included as IL-10, have been found to regulate type 1 responses during infection during a secondary parasitic challenge in the best available mouse model for human severe malaria, demonstrating a regulatory role in the control of pathogenic responses [44].

Nevertheless little information regarding the immunological events underlying the recurrent malaria episodes are currently available. In the present study, the ex vivo phenotypic features of circulating leukocyte subsets as well as the plasmatic cytokine profile were assessed, aiming at establishing patterns of immune response characteristic of recurrent malaria.

\section{Methods}

\section{Study population}

This was a cross-sectional study performed during 10 months with malaria patients seeking for healthcare at the Ambulatory of the Fundação de Medicina Tropical Dr. Heitor Vieira Dourado (FMT-HVD), Manaus, Amazonas State, Brazil. The selection of malaria patients was performed by convenience, excluding individuals with chronic/degenerative diseases or pregnant women. Only those patients with positive microscopic diagnosis of $P$. vivax infection with parasitaemia higher than 500 parasite $/ \mathrm{mm}^{3}$ were included in the study. Two sets of patients were selected for this study: patients with "primary malaria" and "recurrent malaria". The inclusion criteria for cases of $P$. vivax "recurrent malaria" were defined as patients that presented new malaria infection within a six-month interval apart from the last episode. The occurrence of relapse/recrudescence episodes was minimized, since all patients with "recurrent malaria" underwent therapeutic regimens as recommended by the Brazilian Ministry of Health to $P$. vivax malaria (chloroquine for 3 days and primaquine for 7 or 14 days) [45-48], with strict follow-up after treatment to monitor therapeutic effectiveness, according to FMT-HVD guidelines for cure-monitoring. The periodic cure-monitoring consisted of microscopic examination of thin and thick blood smears during the first 2 months $(2,4,7,14,21,28$, 40 and 60 days) after the initiation of treatment. In cases of positive microscopic results after the maximum time limit specified above, but before 6 months, the patients should be classified as new cases or "recurrent malaria". Using this criterion, 13 patients with presumed "recurrent malaria" were excluded, as they reported presented parasitaemia levels lower than 500 parasite $/ \mathrm{mm}^{3}$.

Fifty-five patients with $P$. vivax mono-infection [49], age ranging from 16 to 70 years, 39 males and 16 females, all presenting negative serology for dengue virus 
infection, were selected to compose the malaria group. Upon clinical evaluation, malaria patients were categorized into two subgroups referred as: "primary malaria" $(\mathrm{n}=36)$ and "recurrent malaria" $(\mathrm{n}=19)$.

Twenty healthy subjects, resident in the same geographic area was enrolled as the "endemic control" group, with age ranging $19-48$ years, nine man and 11 women.

\section{Ethical issues and blood sampling}

This study was approved by the Ethics Committee and the Superior Council at FMT-HVD (CAEE process \#0044.0.114.000-11). Each participant read and signed the written informed consent form. EDTA whole blood samples $(5 \mathrm{~mL})$ were collected from each participant. All patients were treated according to the recommendations provided by the Brazilian Ministry of Health.

\section{Assessment of Plasmodium vivax mono-infection status}

Total genomic DNA was extracted from EDTA whole blood samples, using the gDNA Blood kit (Invitrogen ${ }^{\mathrm{TM}}$, Carlsbad, CA, USA), following the instructions provided by the manufacturer. Plasmodium vivax mono-infection status was confirmed by Nested PCR, in the presence of specific oligonucleotides for $P$. vivax, $P$. falciparum and Plasmodium malariae, according to the protocol described by Snounou and Singh [50].

\section{Monoclonal antibody panel for immunophenotypic analyses}

Anti-human cell surface/cytoplasm monoclonal antibody (mAbs) panel labeled with distinct fluorochromes were used for flow cytometric immunophenotypic analysis, including: anti-CD3-PECy7(SK7), anti-CD4-PE(RPA-T4), anti-CD8-FITC(HIT8a), anti-CD69-APC(FN50), anti-CD25PERCP-Cy5(M-A251),anti-FoxP3-AF647(259D/C7),anti-CD19FITC(HIB19), anti-CD5-PE(UCHT2), anti-CD16-FITC(3G8) and anti-CD56-PE(B159), all purchased from BD Bioscience, San Diego, CA, USA.

\section{Haematological parameters and flow cytometric analysis of lymphocyte subsets}

EDTA whole blood samples were employed for assessing haematological parameters using an automated haematological analyzer (Sysmex KX-21 $\mathrm{N}^{\circledR}$ ). An additional flow cytometric immunophenotypic analysis was also carried out as follows: briefly, $50 \mathrm{~mL}$ aliquots of whole blood were incubated with $5-10 \mathrm{~mL}$ of fluorescent mAbs for $30 \mathrm{~min}$, at room temperature, in the dark. After incubation, the red blood cells were lysed with $2 \mathrm{~mL}$ of lysing solution (BD FACS ${ }^{\mathrm{TM}}$ Lysing Solution, BD ${ }^{\circledR}$ Biosciences San Diego, CA, USA) for $10 \mathrm{~min}$ at room temperature, in the dark. For FoxP3 immunostaining, cells were permeabilized for $10 \mathrm{~min}$ at room temperature, in the dark with
$2 \mathrm{~mL}$ of perm buffer (phosphate-buffered saline-PBS, $0.5 \%$ saponin, $0.5 \%$ bovine serum albumin). After one wash step with PBS, stained cells were fixed in FACS fix solution (10 g/L of paraformaldehyde, $10.2 \mathrm{~g} / \mathrm{L}$ of sodium cacodylate and $6.63 \mathrm{~g} / \mathrm{L}$ of sodium chloride, $\mathrm{pH}$ 7.2). Cells were run in a FACSCanto $\mathrm{II}^{\circledR}$ flow cytometer (BectonDickinson Company, San Jose, CA, USA) and a total of 10,000 (100,000 for CD4/CD25/FoxP3) events collected for data analyses. Lymphocyte subsets were quantified first by specific gating strategies, using the FlowJo software (version 9.4.1, TreeStar Inc. Ashland, OR, USA) as represented in Additional file 1. The results were expressed initially as percentage of positive cells within the lymphocyte gate. Absolute counts for lymphocyte subsets were calculated by multiplying the percentage of gated lymphocytes obtained by flow cytometry by the absolute lymphocyte count provided from the automated haematological analyzer.

\section{Plasmatic cytokine quantification}

The plasmatic cytokines were quantified by human Cytometric Bead Array kit for IL-2, IL-4, IL-6, IL-10, TNF and IFN- $\gamma$, all purchased from BD Biosciences Pharmingen (San Diego, CA, USA), following the instructions provided by the manufacturer. Data analysis was performed using the FCAP ArrayTM software, V.2.0 (BD Biosciences, San Jose, CA, USA). Initially, the mean fluorescence intensity (MFI) of each bead cluster was determined and forth logistic regression applied to build the standard curves. Cytokine concentrations for each sample were then extrapolated from the standard curves and data was expressed as $\mathrm{pg} / \mathrm{mL}$ for each plasmatic cytokine.

\section{Data mining and statistical analysis}

Statistical analyses were carried out using the GraphPad Prism software, version 5.0 (San Diego, CA, USA). Comparative analyses of continuous variables (age, haematological parameters, leukocyte subsets and plasmatic cytokines) amongst groups (endemic controls vs primary malaria vs recurrent malaria) were performed by Kruskal-Wallis followed by multiple comparisons performed by Dunn's post-test.

The analysis of overall biomarker profile was performed by converting the original data (leukocyte subsets and plasmatic cytokine profile), obtained as continuous variables, into categorical parameters using the global median cut-off calculated for the study population. Global median values for each haematological parameter, lymphocyte subset and plasmatic cytokine were used to segregate and calculate the proportion of subjects with high biomarker levels (above the cut-off edge). The data were assembled as proposed previously by Luiza-Silva et al. [47] and Souza-Cruz et al. [48] and 
the biomarker profile for endemic controls used as reference curve for comparative analyses with malaria patients. The $\chi^{2}$ test was used to compare the proportions of subjects with biomarker levels above the cut-offs amongst groups.

Spearman's test was used to sort variables that provided significant correlation. Linear regression analysis was applied to generate the best fitted line and the $95 \%$ confidence interval bands.

In all cases, significance was considered at $\mathrm{p}<0.05$. Significance level was underscored by asterisks, as follows: ${ }^{(*)}$ if $\left.\mathrm{p}<0.05 ;{ }^{* * *}\right)$ if $\mathrm{p}<0.005$ and $\left({ }^{* * *)}\right)$ if $\mathrm{p}<0.0005$.

\section{Results}

\section{Compendium of the study population, demographic and haematological parameters}

A flowchart illustrating a compendium of the study population is shown in Fig. 1. Sixty-eight subjects were first enrolled in the present investigation due to their history of exposure to the malaria. Fifty-five patients fulfilled the inclusion criteria and were selected for the study, including 36 patients with primary malaria and
19 patients with at least one recurrent malaria episode within 6 months after post-therapeutic monitoring period. Demographic and haematological parameters of malaria patients as well as the subjects selected as endemic controls $(n=20)$ are presented in Table 1 . Data analysis did not demonstrate any significant difference in the red blood cell (RBC) counts, haemoglobin levels and haematocrit amongst patients with malaria (whether primary or recurrent) and the endemic controls. Both malaria groups presented lower platelet numbers as compared to endemic controls $(p<0.001)$. The white blood cell (WBC) counts by multiple comparisons showed a reduction in both groups with malaria in relation to the endemic control individuals $(p=0.018)$. Malaria patients (primary and recurrent) presented lower lymphocyte counts as compared to endemic controls $(\mathrm{p}<0.001)$. Patients with primary malaria showed reduced monocyte counts as compared to endemic controls $(\mathrm{p}=0.014)$. No changes in the neutrophil counts were observed amongst groups (Table 1). Thrombocytopaenia and lymphopaenia are frequently noted in individuals with malaria $[23,51]$.

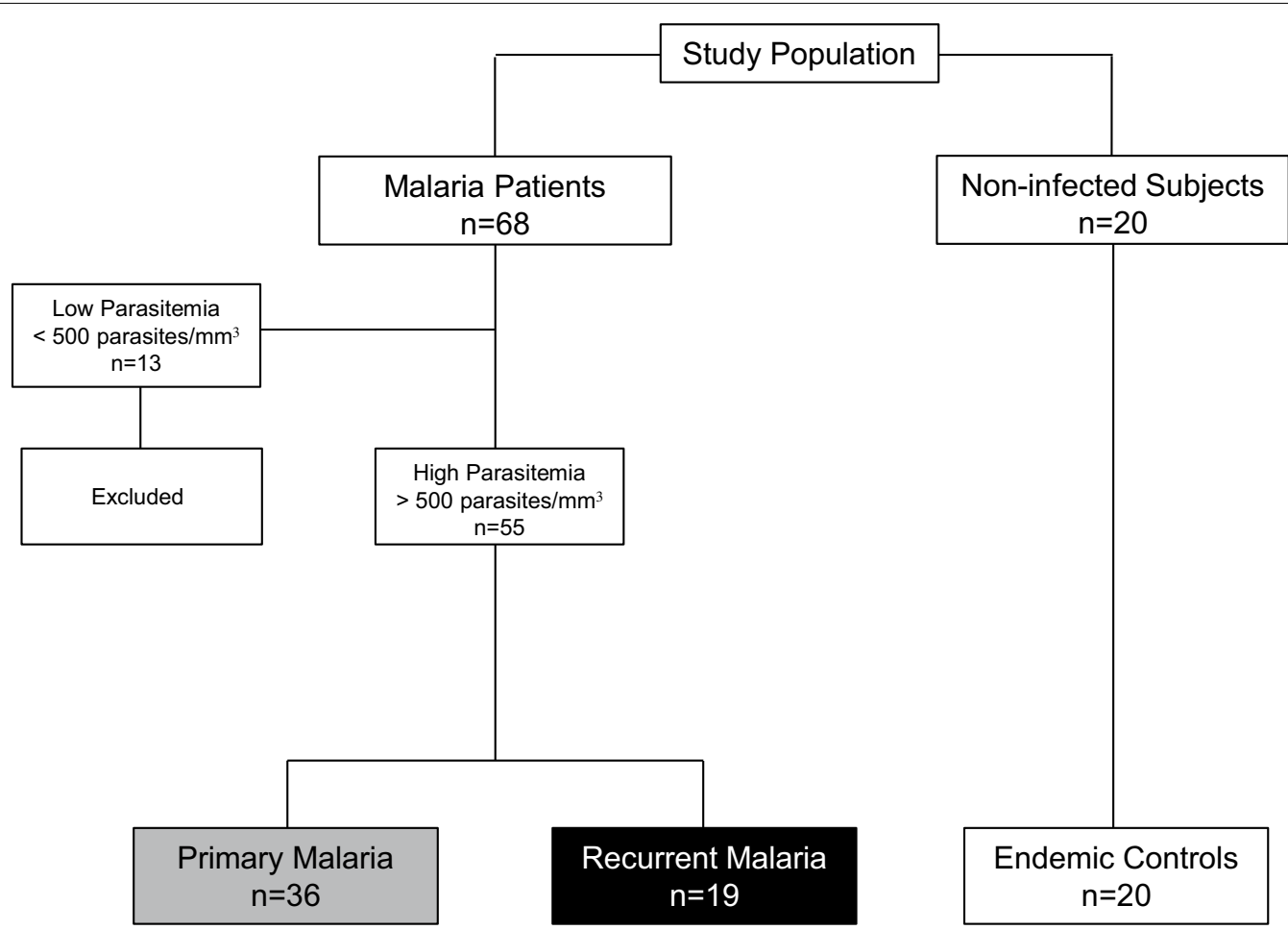

Fig. 1 Compendium of the study population. The study enrolled malaria patients seeking for healthcare at the Ambulatory of the Fundação de Medicina Tropical Dr. Heitor Vieira Dourado (FMT-HVD), Manaus, Amazonas State, Brazil. The patient selection was performed by convenience. From the 68 patients participating in the initial inquiry, fifty-five were selected and included in the study, as patients fulfilled the inclusion criteria (parasitaemia was above 500 parasites $\left./ \mathrm{mm}^{3}\right)$. The selected patients were grouped as: primary malaria $(n=36)$ and recurrent malaria $(n=19)$ as described in "Methods" section. Twenty healthy individuals living in the same endemic area and with no history of malaria were invited to participate as endemic controls 
Table 1 Demographic and haematological parameters of the study population

\begin{tabular}{|c|c|c|c|c|}
\hline & Endemic control $(n=20)$ & Primary malaria $(n=36)$ & Recurrent malaria $(n=19)$ & p value* \\
\hline Age (years), mean (SD) & $27.1(7.4)$ & $35.4(14.3)$ & $39.5(12.0)$ & 0.005 \\
\hline Man/woman (\%) & $45 / 55$ & $64 / 36$ & $85 / 15$ & - \\
\hline Malaria episodes ${ }^{a}$ & - & - & $3.0(1.5-4.0)$ & - \\
\hline Last malaria attack ${ }^{\mathrm{b}}$ & - & - & $4.0(3.0-6.0)$ & - \\
\hline \multicolumn{5}{|l|}{ Haematological parameters ${ }^{c}$} \\
\hline $\mathrm{RBC} \times 10^{3} / \mathrm{mm}^{3}$ & $4.8(4.5-5.4)$ & $4.7(4.2-5.3)$ & $5.0(4.4-5.2)$ & 0.839 \\
\hline Haemoglobin (g/dL) & $13.2(12.5-14.1)$ & $13.4(11.5-14.4)$ & $13.1(12.2-14.1)$ & 0.592 \\
\hline Haematocrit (\%) & $43.9(40.5-46.8)$ & $41.9(36.5-45.7)$ & $42.0(39-46.5)$ & 0.461 \\
\hline Platelets $\times 10^{3} / \mathrm{mm}^{3}$ & $289.0(212.5-325.2)$ & $69.0(37.8-100.5)^{d}$ & $112.0(53-120)^{d}$ & $<0.001$ \\
\hline $\mathrm{WBC} \times 10^{3} / \mathrm{mm}^{3}$ & $6.7(6.1-7.8)$ & $5.7(4.0-7.3)$ & $5.6(4.7-6.8)$ & 0.018 \\
\hline Lymphocytes $\times 10^{3} / \mathrm{mm}^{3}$ & $2.0(1.6-2.6)$ & $1.3(0.7-1.8)^{d}$ & $1.0(0.5-1.3)^{d}$ & $<0.001$ \\
\hline Monocytes $\times 10^{3} / \mathrm{mm}^{3}$ & $0.7(0.5-0.8)$ & $0.3(0.2-0.5)^{d}$ & $0.5(0.3-0.9)$ & 0.014 \\
\hline Neutrophils $\times 10^{3} / \mathrm{mm}^{3}$ & $3.8(3.5-5.1)$ & $3.3(2.1-5.1)$ & $4.0(3.0-4.7)$ & 0.436 \\
\hline
\end{tabular}

Patients were grouped according to their malaria diagnosis based on microscopy data

a The patients were tested at one time point and recurrent malaria episodes recorded

b Time in months

c Data expressed as median and interquartile range (IQR25-IQR75)

d Significant differences as compared to endemic controls

* Kruskal-Wallis analyses followed by Dunn's post-test

\section{Biomarker profiles of primary malaria vs recurrent malaria} In order to compare the overall biomarker profiles for primary malaria and recurrent malaria, the continuous variables obtained originally were converted into categorical parameters using cut-off calculated for the study population. The results were reported as the proportion of subjects with high biomarker levels above the cut-offs calculated for the study population (Fig. 2). The biomarker profile for endemic controls was used as reference curve for comparative analyses with malaria patients. Data analysis showed a reduction in the proportion of subjects with high levels of WBC as compared to the endemic control reference curve. It was also observed decreased proportion of subjects with high levels of monocytes particularly in patients with primary malaria (Fig. 2). Moreover, the proportion of subjects with high levels of all lymphocyte subsets was decreased in all malaria groups, regardless their clinical status. Analyses of lymphocyte subsets showed significant decrease in the proportion of subjects with high levels of CD4 ${ }^{+}$T-cells ( $\mathrm{p}=0.036)$ and $\mathrm{CD}^{+} \mathrm{T}$-cells $(\mathrm{p}=0.0034)$, particularly in the group of patients with recurrent malaria (Fig. 2). These cell subsets have a relevant role in malaria, controlling the infection or associated with pathogenesis of severe forms of the disease, depending on their cytokine profiling [52].

The proportion of subjects with high levels of cytokines demonstrated a reversal picture characterizing a typical cytokine storm. Data analysis indicated significant increase in the proportion of the subjects with high cytokine levels in both malaria groups (Fig. 2). It was also noted an increased proportion of subjects with high plasmatic IL-10 levels, selectively in patients with recurrent malaria ( $\mathrm{p}=0.011$ ). This was an interesting finding, since IL-10 is a well-known biomarker with regulatory role on inflammatory processes and for being directly associated to the protection in severe malaria [53]. Finally, this global analysis allowed for verifying that recurrent malaria is associated with a particular biomarker profile, characterized by decreased levels of the $\mathrm{CD}^{+}$and $\mathrm{CD} 8^{+}$ T-cells along with a significant increase in the IL-10 production (Fig. 2).

\section{Ex vivo phenotypic features of circulating T-cell subsets}

The global analysis of categorical data has identified significant differences in the immune response associated with primary and recurrent malaria. Aiming at establishing useful laboratorial tools to monitor the immunological status of patients with primary and recurrent malaria, the ex vivo phenotypic features of circulating T-cell subsets were evaluated as continuous variables (Fig. 3). Data analysis confirmed that both malaria groups presented decreased absolute counts of $\mathrm{CD}^{+}{ }^{+}$and $\mathrm{CD} 8^{+}$T-cells as compared to endemic controls (Fig. 3a, d). In addition, lower levels of $\mathrm{CD}^{+} \mathrm{T}$-cells was observed in patients with recurrent malaria as compared to primary malaria (Fig. 3d). The analysis of activated T-cells demonstrated that both malaria groups presented significantly lower 


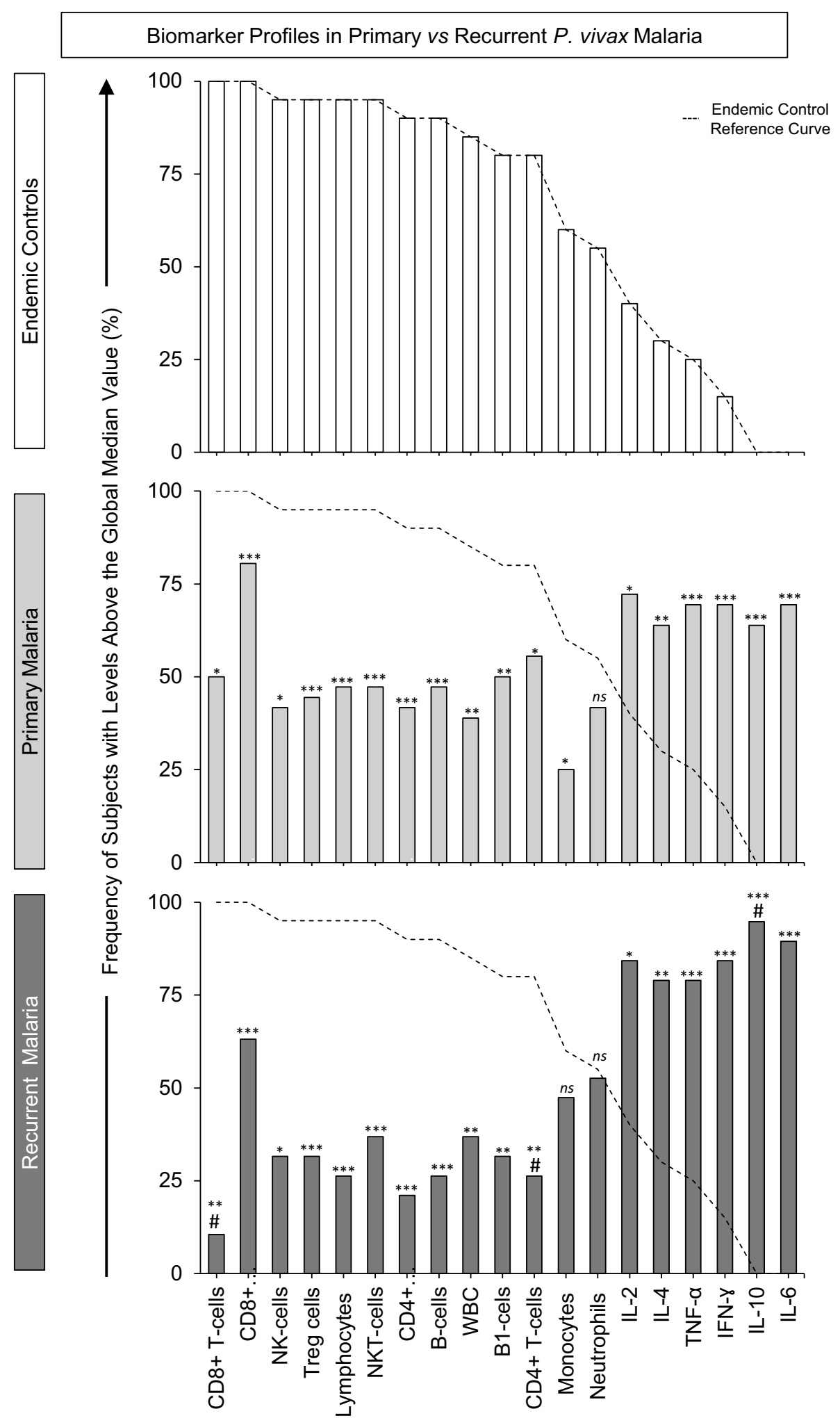




\section{(See figure on previous page)}

Fig. 2 Biomarker profiles of primary malaria vs recurrent malaria. The biomarker profiles were performed by converting the original data (leukocyte subsets and plasmatic cytokine profile), obtained as continuous variables, into categorical parameters. The results were reported as the proportion of subjects with high biomarker levels above the cut-offs calculated for the study population, as described in "Methods" section. The data were arranged as descendent biomarker profile for endemic controls (white bars), and used as reference curve (dotted line) for comparative analyses with malaria patients (primary malaria $=$ light-gray bars and the recurrent malaria $=$ dark-gray bars). The $x^{2}$ test was used to identify significant differences at $p<0.05$. Asterisks represents the significance levels $\left({ }^{*} p<0.05,{ }^{* *} p<0.005\right.$ and $\left.{ }^{* * *} p<0.0005\right)$. Significant differences between primary and recurrent malaria were represented by hash

counts of $\mathrm{CD} 4^{+} \mathrm{CD} 69^{+}$and $\mathrm{CD} 8^{+} \mathrm{CD} 69^{+}$as compared to endemic controls (Fig. 3b, e). Moreover, patients with recurrent malaria displayed decreased absolute counts and percentage of $\mathrm{CD} 4^{+} \mathrm{CD} 69^{+}$and $\mathrm{CD} 8^{+} \mathrm{CD} 69^{+}$as compared to primary malaria (Fig. 3b, c, e, f).

\section{Ex vivo phenotypic features of circulating NK and NKT, Treg and B-cells}

The ex vivo phenotypic features of circulating NK and NKT, Treg and B-cells, evaluated as continuous variables, are presented in Additional file 2. The results showed a decrease in NKT, Treg, B, and B1 cells in malaria patients as compared to the endemic controls, with no differences between primary and recurrent malaria (Additional file 2).

\section{Plasmatic cytokine profiles in primary malaria vs recurrent malaria}

The categorical analysis of plasmatic cytokine indicated that regardless their clinical status, all malaria patients presented a typical cytokine storm and also pointed out that patients with recurrent malaria group exhibited enhanced proportion of subjects with high IL-10 levels (Fig. 2). In order to further characterize these immunological biomarkers, the plasmatic cytokine levels were quantified as continuous variables (Fig. 4). The data analysis demonstrated that both malaria groups have significantly increased levels of IL-2, IL-4, IL-6, IL-10, TNF and IFN- $\gamma$ as compared to the endemic controls. Moreover, the recurrent malaria group displayed significantly augmented levels of IL-10, IL-6, and IL-4 as compared to patients with primary malaria $(\mathrm{p}<0.0005, \mathrm{p}<0.005$ and $\mathrm{p}<0.05$, respectively) (Fig. $4 \mathrm{a}-\mathrm{c}$ ).

\section{Association between T-lymphocyte subsets, plasmatic IL-10 levels and number of recurrent malaria episodes}

The immune response induced by recurrent malaria revealed significant changes in the main T-cells subsets and also in relevant cytokines, particularly IL-10. Intending to verify the existence of associations amongst these variables, correlation analysis were carried out and data are presented in Fig. 5. The results demonstrated a significant positive correlation between the $\mathrm{CD}^{+} / \mathrm{CD}^{+}$ T-cells (ratio) and plasmatic IL-10 levels (pg/mL) selectively in recurrent malaria patients (Fig. $5 \mathrm{a}-\mathrm{c}$ ).
To add new insights to this issue, the hypothesis as to whether there is any association between IL-10 levels and the number of malaria episodes was then tested. Intergroup multiple comparisons revealed that, besides the higher IL-10 levels observed in all malaria subgroups (primary, 2-3 recurrent and $>4$ recurrent episodes) as compared to endemic controls, there was clear and progressive increase in the IL-10 levels according to the number of malaria episodes (Fig. 5d). Such finding reinforces the hypothesis of relevant role of the IL-10, particularly in recurrent malaria.

\section{Discussion}

Plasmodium vivax is highly prevalent around the world [1]. Regardless its former association with benign malaria [3, 22], complications of P. vivax malaria have been reported in adult patients living in Amazon Basin endemic areas $[11,12]$. It has been proposed that a balance between the pro- and anti-inflammatory responses can account for the control against the development of the severe malaria episodes [54].

Infections with Plasmodium ssp. are capable of inducing major changes in leukocyte profiling [9, 55-62]. In the present study, data demonstrated that patients with $P$. vivax recurrent malaria presented an unbalanced $\mathrm{CD}_{4}^{+} /$ $\mathrm{CD}^{+}{ }^{+}$T-cell ratio, which was associated with a significant increase in the plasmatic IL-10 levels. Interestingly, it was verified that the IL-10 levels in patients with recurrent malaria were directly proportional to the number of malaria episodes.

In details, the ex vivo phenotypic profile of circulating leukocytes was characterized in patients with $P$. vivax primary and recurrent malaria. Relevant changes in the proportion of subjects with high levels of circulating lymphocyte subsets were found (Fig. 2). In particular, patients with recurrent malaria presented significant reduction of $\mathrm{CD} 4^{+}, \mathrm{CD} 8^{+}$T-cells and activated T-cells (CD69-expressing $\mathrm{CD}^{+}{ }^{+}$and $\mathrm{CD}^{+}{ }^{+} \mathrm{T}$-cells) (Fig. 3). The reduction among those subpopulations was also evident in other studies carried out with $P$. vivax naturally infected individuals $[55,59,63,64]$. Those authors interpreted the reduction in the lymphocyte subpopulations in the peripheral blood as a suppressant effect in the response to the $P$. vivax $[55,56,63-65]$. According to them, such reduction could be due to the high apoptosis 


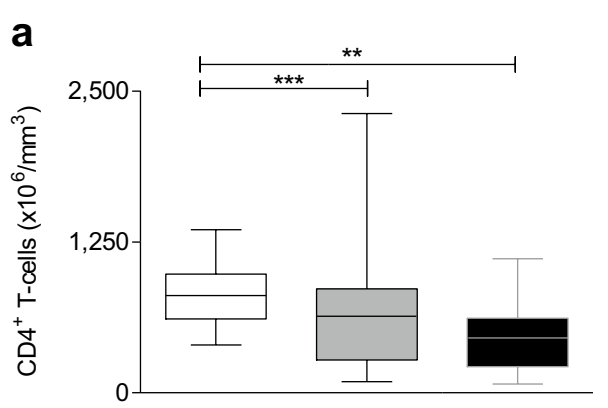

b
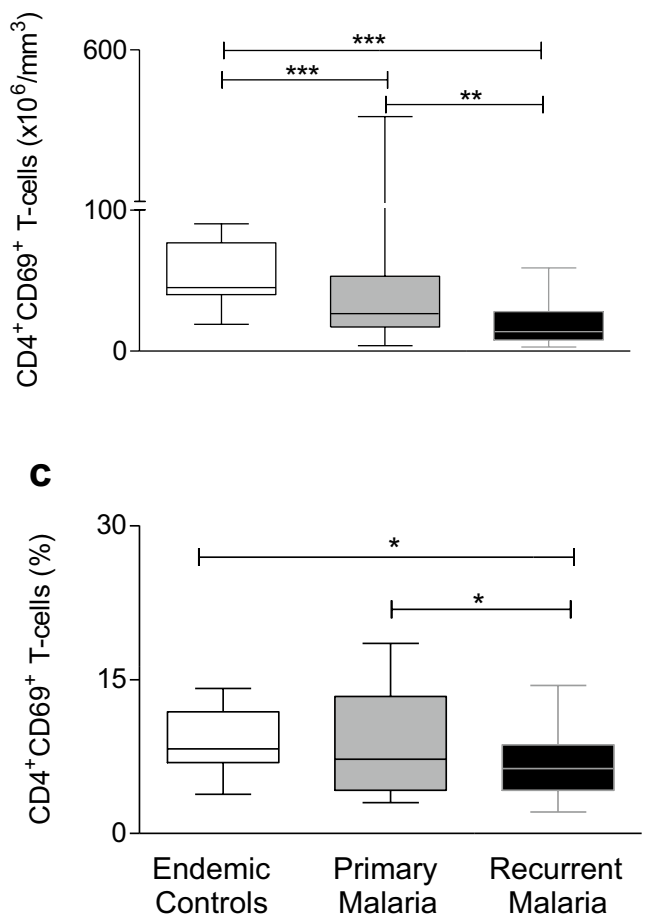

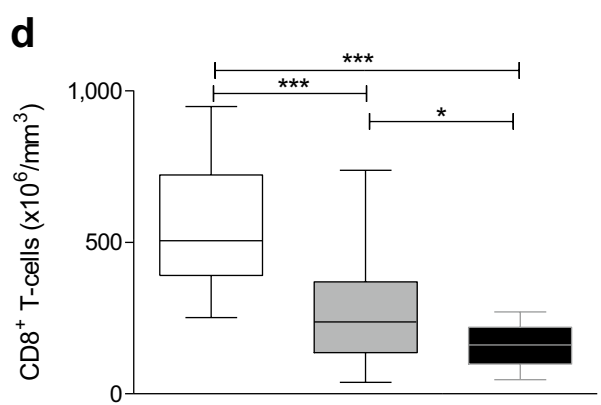

e

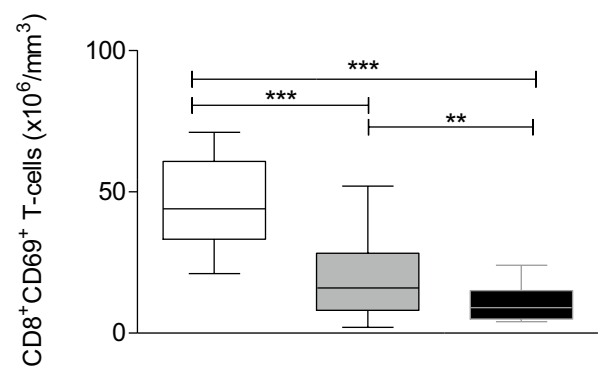

f

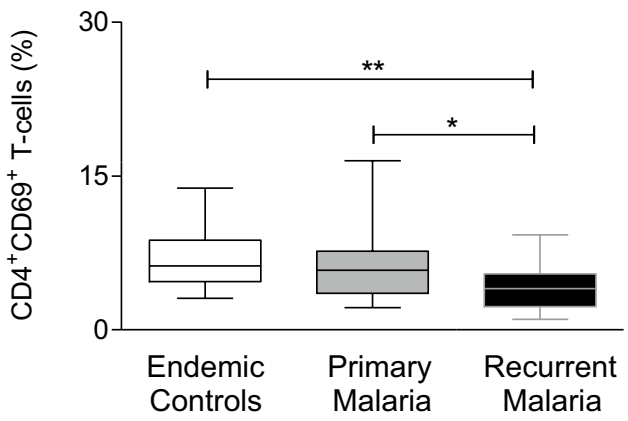

\section{Clinical Groups}

Fig. 3 Ex vivo phenotypic features of circulating T-cell subsets. The levels and activation status of T-cell subsets were assessed in patients with primary malaria, recurrent malaria as well as endemic controls, including: a CD4 ${ }^{+} \mathrm{T}$-cells; $\mathbf{b} \mathrm{CD} 4^{+} \mathrm{CD} 69^{+} \mathrm{T}$-cells; $\mathbf{c} \% \mathrm{CD} 4^{+} \mathrm{CD} 69^{+} \mathrm{T}$-cells, d CD8 ${ }^{+} \mathrm{T}$-cells; e $\mathrm{CD} 8^{+} \mathrm{CD} 69^{+} \mathrm{T}$-cells; $\mathbf{f} \% \mathrm{CD} 8^{+} \mathrm{CD} 69^{+} \mathrm{T}$-cells. Data are displayed in boxplot format (min to max, IQR25-IQR75 and median) of absolute counts (a, b, $\mathbf{d}$ and $\mathbf{e}$ ) and percentage (c and $\mathbf{f}$ ) of T-cell subsets. Multiple comparisons amongst groups were performed by Kruskal-Wallis, followed by Dunn's post-test. Significance differences are represented by ${ }^{*} p<0.05$; $^{* *} p<0.005$ and ${ }^{* * *} p<0.0005$

levels or to the relocation of the cells in the liver and in other lymphoid compartments [55, 64, 66-68]. In the present study, the major changes, occurred in T-lymphocyte subsets, were observed in the group with recurrent malaria; however, further investigations must be performed to elucidate it, as the phenomenon is more accentuated in this group.

Comparison of plasmatic cytokine levels showed specific characteristics suggestive of a massive cytokine storm in patients with primary and recurrent malaria as compared to healthy endemic controls (Fig. 2). In malaria patients, the levels of IL- 6 and IL-10 were increased expressively in relation to other cytokines (Fig. 4), supporting what was noted in other studies on non-complicated malaria [69-72]. It is well established that the unbalance of the pro- and anti-inflammatory mediators is a fundamental component in the malaria pathogenesis by the $P$. vivax $[9,35,46,58,64,73-76]$. In this study, levels 


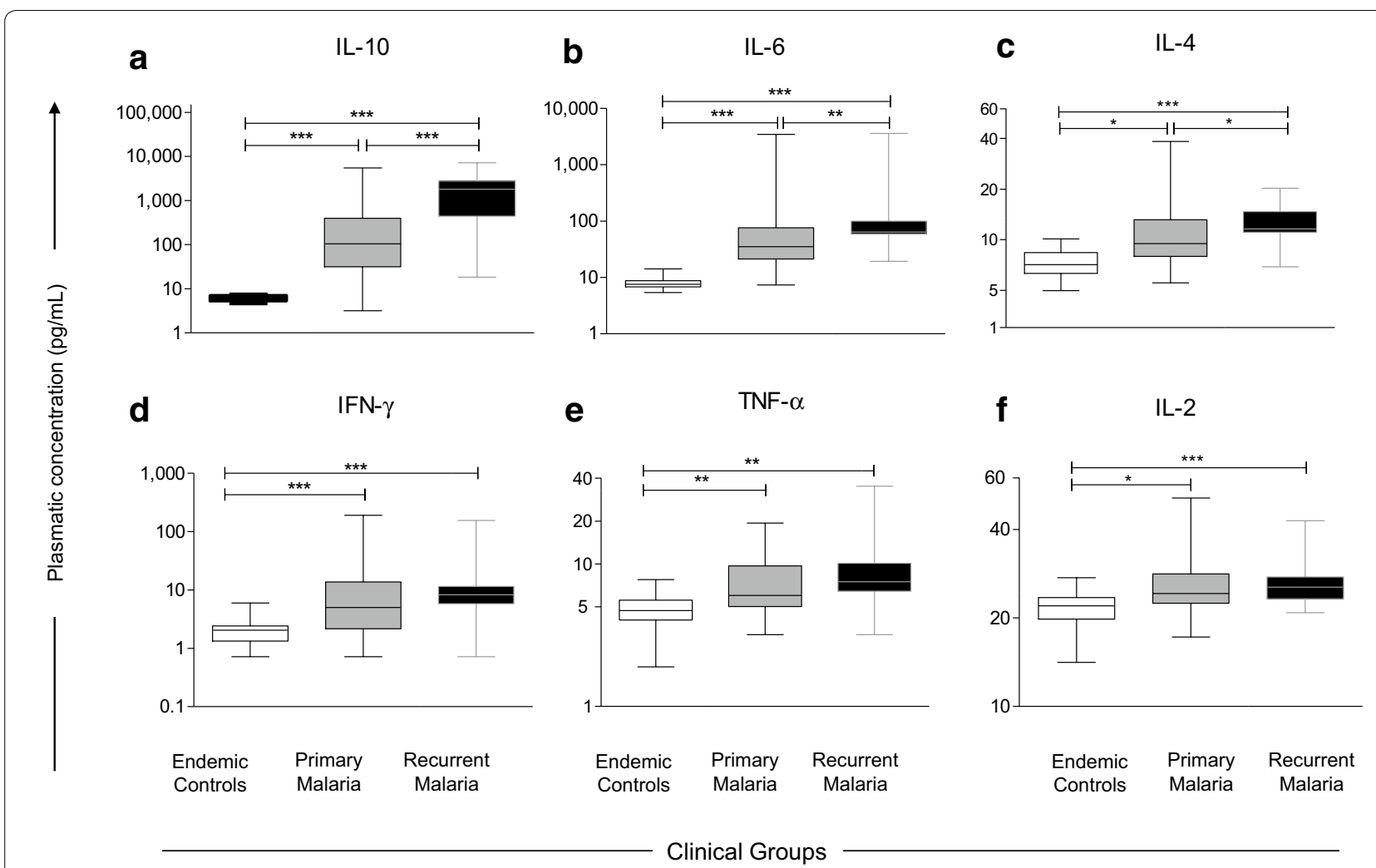

Fig. 4 Plasmatic cytokine profiles in primary malaria vs recurrent malaria. The plasmatic cytokine levels were quantified in patients with primary malaria, recurrent malaria as well as endemic controls, using cytometric bead array as described in "Methods" section. The analysis included: a IL-10; $\mathbf{b}\|\mathrm{L}-6 ; \mathbf{c}\| \mathrm{L}-4 ; \mathbf{d} \mathrm{IFN}-\gamma ; \mathbf{e}$ TNF-a and $\mathbf{f} \| \mathrm{L}-2$. Data are expressed in $\mathrm{pg} / \mathrm{mL}$. Multiple comparisons amongst clinical groups were performed by KruskalWallis, followed by Dunn's post-test. Significance differences are represented by ${ }^{*} p<0.05$; ** $p<0.005$ and ${ }^{* * *} p<0.0005$

of the IL-10, IL-6 and IL-4 were higher in patients with recurrent malaria. Nonetheless, it could not be directly compared to data found in the literature due to the different methodology used. It must be mentioned that no patient participating in this study developed any complication during the acute infection. This is an important indication that within a short period of time, recurrent infections by the $P$. vivax did not increase the risk for complications, as reported previously in other studies $[77,78]$. Probably, such risk is associated to the hyperreactivity of the immune system, as it is verified in African children after recent malaria episode [79-81].

Although several studies have shown the dynamics of the subpopulations during $P$. vivax infection, the correlation between such findings and the number of malaria episodes were less explored [9, 55-62]. The findings indicate a direct association between the $\mathrm{CD} 4^{+} / \mathrm{CD} 8^{+} \mathrm{T}$-cells ratio and plasmatic IL-10 cytokine levels, selectively in patients with recurrent malaria (Fig. 5). Recent studies determined that after the first malaria infection, the T-cells secreting IL-10 are more stable and have a longer life span as compared to IFN- $\gamma$-producing T-cells [82-84].
Supporting these findings, the data presented here demonstrated that the levels of IL-10 were directly proportional to the number of malaria episodes $[64,83,84]$. Several reports have proposed that the resistance pattern or susceptibility to the infection by the Plasmodium is related to the cytokine microenvironment, with resistance to the parasite relying on cytokines such as IFN- $\gamma$, TNF, IL-12, and GM-CSF, while susceptibility is associated to the IL-10, IL- 4 and TGF- $\beta[43,85]$.

The IL-10 plays an important effect inasmuch as it is capable of deactivating macrophages, and it is indirectly responsible by decreasing the production of the IFN- $\gamma$. In this way, IL-10 actuates by cushioning the potentially harmful effects of the macrophage activation on the host tissue [86]. In this study, the high production of IL-10 was remarkable in patients with recurrent malaria, being very low in patients with primary malaria. IL-10 has been indicated as an important regulator of the harmful immune responses to the host [87]. However, due to its inhibitory ability over the macrophagic hyperactivation, the secretion of such cytokine would reduce the control of the host over the circulating parasites, thus possibly favoring the relapse of the infection [85]. 

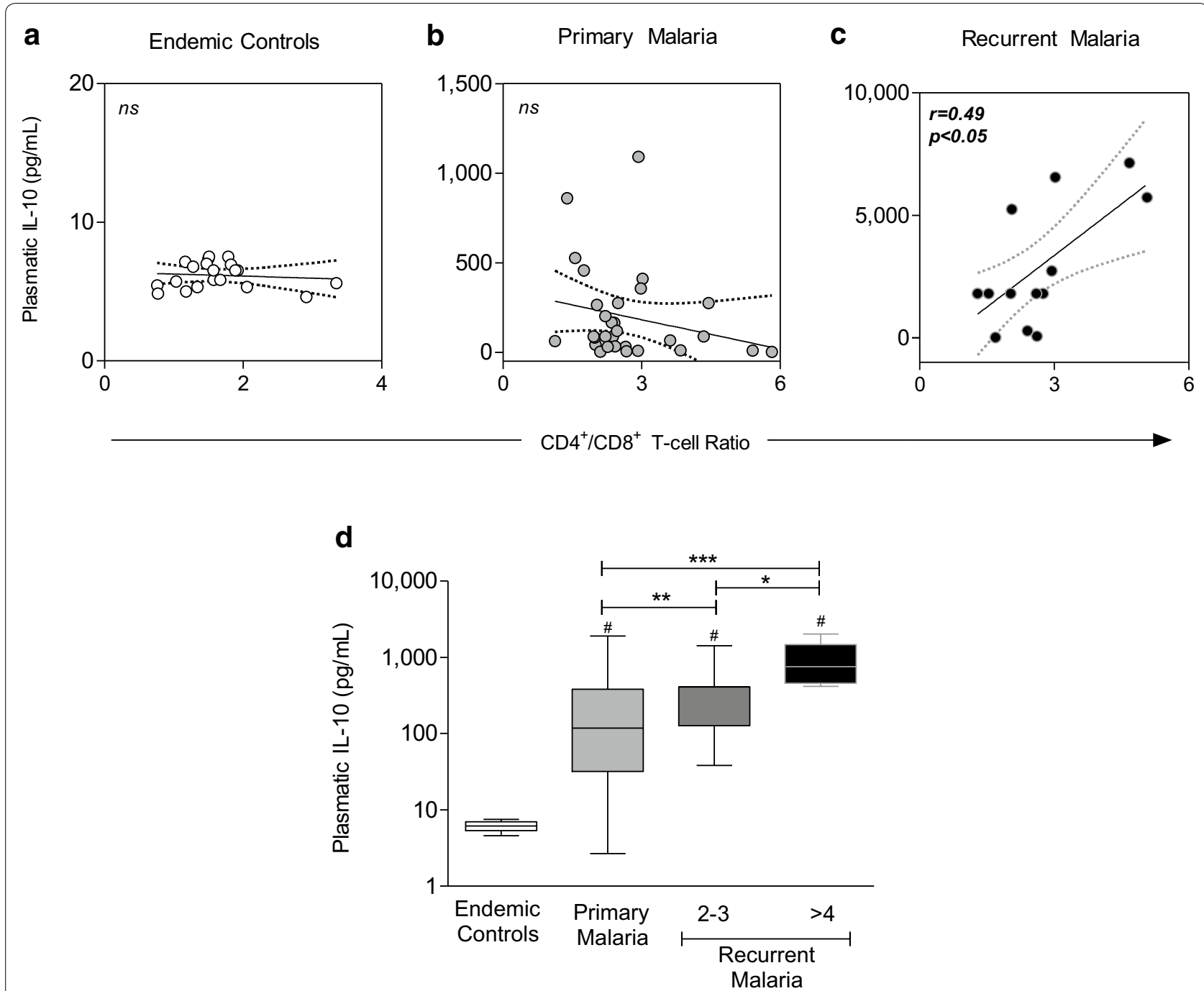

Fig. 5 Association between T-lymphocyte subsets, plasmatic IL-10 levels and number of recurrent malaria episodes. Spearman correlation analysis was applied to identify the association between the $\mathrm{CD}^{+} / \mathrm{CD}^{+}$T-cells (ratio) and the plasmatic IL-10 levels (pg/mL) for $\mathbf{a}$ endemic controls, $\mathbf{b}$ primary malaria and $\mathbf{c}$ recurrent malaria. Assessment of the IL-10 levels related to the previous exposition to the malaria. Additional analysis of IL-10 levels ( $\mathrm{pg} / \mathrm{mL}$ ) in malaria patients categorized according to the number of malaria episodes (primary, 2-3 recurrent and $>4$ recurrent episodes) as compared to endemic controls were also carried out (d). Data are displayed in boxplot format (min to max, IQR25-IQR75 and median). Multiple comparisons amongst clinical groups were performed by Kruskal-Wallis, followed by Dunn's post-test. Significance differences are represented by ${ }^{*} p<0.05 ;{ }^{* *} p<0.005$ and ${ }^{* * *} p<0.0005$

One of the limitations of this study was the impossibility to define which mechanisms are involved in the development of the recurrent infection, considering the multiple etiological factors involved in this phenomenon. Nevertheless, the data indicate the crucial immunoregulatory effect of the IL-10 in recurrent infections. It is also required that further investigation should be undertaken to shed light on the association between the decreased
$\mathrm{CD} 4^{+} / \mathrm{CD}^{+}$T-cell ratio and the increased plasmatic IL-10 levels during recurrent malaria. The findings suggest that the gradual immunity acquisition is dependent on the exposition involving a control of the immune response mediated by IL-10. Future prospective studies are required in order to assess the risk factors associated to the relapse of the $P$. vivax malaria and its relationship with different components of the immune response. 


\section{Conclusion}

Although this study has been conducted with a relatively small number of patients, our findings have shown that recurrent malaria, within 6 months after the end of therapeutic monitoring period, induces a relevant IL-10-mediated response, suggesting the occurrence of a gradual acquisition of modulatory immunity. The present study is a descriptive investigation and does not report the mechanisms underlying the development of distinct patterns of immune response in patients with recurrent malaria. The hypothesis that IL-10 would have a protective role against complications of recurrent malaria still requires further investigation. It is important to keep in mind that, due to its modulatory activity, the high levels of the IL-10 would also favor the occurrence of recrudescence/relapse of $P$. vivax malaria.

\section{Additional files}

\begin{abstract}
Additional file 1. Representative flow cytometric analysis of lymphocyte subsets. Peripheral blood lymphocytes were first selected based on their morphometric features (size/FSC forward scatter and granularity/SSC side scatter) on pseudocolour plot (A). Following, the phenotypic features were evaluated to quantify cell-substs and the activation status, including, $\mathrm{CD}^{+}$and $\mathrm{CD}^{+}{ }^{+}$-cells (B and $\mathrm{C}$ ); $\mathrm{CD}^{+} 9^{+} \mathrm{CD} 4^{+}$and $\mathrm{CD} 69^{+} \mathrm{CD} 8^{+} \mathrm{T}$-cells (D and $\mathrm{E}) ; \mathrm{CD}_{5}{ }^{+} \mathrm{CD} 16^{+}$within $\mathrm{CD} 3^{-}$events - NK-cells (F), $\mathrm{CD}^{+}{ }^{+} \mathrm{CD} 56^{+} \mathrm{NKT}$ cell (G) FoxP3 ${ }^{+} \mathrm{CD}_{25} 5^{+} \mathrm{CD}_{4}^{+}$within $\mathrm{CD}^{+}$events-Treg cells $(\mathrm{H})$ and $\mathrm{CD} 19^{+}$ B-cells, and $\mathrm{CD} 19^{+} \mathrm{CD} 5^{+} \mathrm{B} 1$-cells (I). All analysis were performed using the FlowJo software (version 9.4.1, TreeStar Inc. Ashland, OR, USA)
\end{abstract}

Additional file 2. Ex vivo phenotypic features of circulating NK and NKT, Treg and B-cells. The levels lymphocyte subsets were assessed in patients with primary malaria, recurrent malaria as well as endemic controls, including: A) NK-cells; B) NKT-cells; C) Treg-cells; D) B-cells; and E) B1-cells. Data are displayed in boxplot format (min to max, IQR25-IQR75 and median). Multiple comparisons amongst clinical groups were performed by Kruskal-Wallis, followed by Dunn's post-test. Significance differences are represented by * for $p<0.05$; ** for $p<0.005$ and ${ }^{* * *}$ for $p<0.0005$

\section{Authors' contributions}

YOC, AGC, PPO and PAN designed, performed the experiments and analysed the data. MVGL, JGCdR, OAMF, ATC, AM, WMM, CRFM and PAN discussed the results. MVGL, PPO and PAN conceived and designed the study. CRFM, MLMP, JGCdR, ATC, OAMF and PAN wrote the manuscript. All authors read and approved the final manuscript.

\footnotetext{
Author details

${ }^{1}$ Instituto Leônidas e Maria Deane, Fundação Oswaldo Cruz (FIOCRUZ), Manaus, AM, Brazil. ${ }^{2}$ Programa de Pós-Graduação em Medicina Tropical, Universidade do Estado do Amazonas (UEA), Manaus, AM, Brazil. ${ }^{3}$ Fundação de Medicina Tropical Dr. Heitor Vieira Dourado (FMT-HVD), Manaus, AM, Brazil. ${ }^{4}$ Departamento de Ensino e Pesquisa, Fundação Hospitalar de Hematologia e Hemoterapia do Amazonas (HEMOAM), Manaus, AM, Brazil. ${ }^{5}$ Departamento de Parasitologia, Instituto de Ciências Biológicas, Universidade de São Paulo (USP), São Paulo, SP, Brazil. ${ }^{6}$ Grupo Integrado de Pesquisas em Biomarcadores de Diagnóstico e Monitoração, Centro de Pesquisas René Rachou, Fundação Oswaldo Cruz (FIOCRUZ), Belo Horizonte, MG, Brazil. ${ }^{7}$ Programa de Pós-Graduação em Imunologia Básica e Aplicada, Universidade Federal do Amazonas (UFAM), Manaus, AM, Brazil.
}

\section{Acknowledgements}

We thank Antonio Balieiro from Instituto de Pesquisas Leônidas and Maria Deane (FIOCRUZ Manaus) for their statistics support and the Grupo Integrado de Pesquisas em Biomarcadores (CpqRR-FIOCRUZ) for technical support.

\section{Competing interests}

The authors declare that they have no competing interests.

\section{Availability of supporting data}

The authors inform that all data presented in this manuscript are available upon request.

\section{Consent for publication}

All authors declare to consent of the manuscript and agree to the proposed authorship order.

\section{Ethics approval and consent to participate}

This study was approved by the Ethics Committee and the Superior Council at FMT-HVD (CAEE Process \#0044.0.114.000-11). Each participant read and signed the written informed consent form to participate of this study.

\section{Funding}

Financial support was provided by grants from FAPEAM, CNPq and Programa do Instituto Nacional de Ciência e Tecnologia em Vacinas (INCT-Vacina). YOC was awarded with a fellowship from INCT-Vacina/CNPq and AGC with a fellowship from CAPES (PhD students). AM and ATC are level 2 CNPq research fellow. MVGL and OAMF are level 1 CNPq research fellows. CRFM, OAMF and ATC are FAPEAM research fellows (PVS Programme - PECTI-AM/PG\#019/2013). JGCdR received postdoctoral fellowship from CAPES (PNPD/CAPES programme). The funders had no role in study design, data collection and analysis, decision to publish, or preparation of the manuscript.

Received: 22 March 2016 Accepted: 23 August 2016

Published online: 31 August 2016

\section{References}

1. Gething PW, Elyazar IRF, Moyes CL, Smith DL, Battle KE, Guerra CA, et al. A long neglected world malaria map: Plasmodium vivax endemicity in 2010. PLoS Negl Trop. Dis. 2012;6:e1814.

2. Lacerda MVG, Fragoso SCP, Alecrim MGC, Alexandre MAA, Magalhaes $B M L$, Siqueira AM, et al. Postmortem characterization of patients with clinical diagnosis of Plasmodium vivax malaria: to what extent does this parasite kill? Clin Infect Dis. 2012;55:e67-74.

3. Anstey NM, Russell B, Yeo TW, Price RN. The pathophysiology of vivax malaria. Trends Parasitol. 2009;25:220-7.

4. Baird JK. Resistance to therapies for infection by Plasmodium vivax. Clin Microbiol Rev. 2009;22:508-34.

5. Baird JK. Evidence and implications of mortality associated with acute Plasmodium vivax malaria. Clin Microbiol Rev. 2013;26:36-57.

6. Astier R, Meyer G, Englender J, Lavergne A, Steg PG, Ménasché P, et al. [/n vitro opening of human atheromatous coronary arteries using a pulsed laser](in French). Arch Mal Coeur Vaiss. 1985;78:1889-94.

7. Tjitra E, Anstey NM, Sugiarto P, Warikar N, Kenangalem E, Karyana M, et al. Multidrug-resistant Plasmodium vivax associated with severe and fatal malaria: a prospective study in Papua, Indonesia. PLoS Med. 2008;5:e128.

8. Kochar DK, Das A, Kochar SK, Saxena V, Sirohi P, Garg S, et al. Severe Plasmodium vivax malaria: a report on serial cases from Bikaner in northwestern India. Am J Trop Med Hyg. 2009;80:194-8.

9. Andrade BB, Reis-Filho A, Souza-Neto SM, Clarêncio J, Camargo LM, Barral $A$, et al. Severe Plasmodium vivax malaria exhibits marked inflammatory imbalance. Malar J. 2010;9:13.

10. Braz RM, Duarte EC, Tauil PL. Caracterização das epidemias de malária nos municípios da Amazônia Brasileira em 2010. Cad Saúde Pública. 2013;29:935-44.

11. Oliveira-Ferreira J, Lacerda MV, Brasil P, Ladislau JL, Tauil PL, Daniel-Ribeiro CT. Malaria in Brazil: an overview. Malar J. 2010;9:115. 
12. Costa FT, Lopes SC, Ferrer M, Leite JA, Martin-Jaular L, Bernabeu M, et al. On cytoadhesion of Plasmodium vivax: raison d'être? Mem Inst Oswaldo Cruz. 2011;106(Suppl 1):79-84.

13. White NJ. Determinants of relapse periodicity in Plasmodium vivax malaria. Malar J. 2011;10:297.

14. Duarte EC, Pang LW, Ribeiro LC, Fontes CJ. Association of subtherapeutic dosages of a standard drug regimen with failures in preventing relapses of vivax malaria. Am JTrop Med Hyg. 2001;65:471-6.

15. Yeung $\mathrm{S}$, White NJ. How do patients use antimalarial drugs? A review of the evidence. Trop Med Int Health. 2005;10:121-38.

16. Markus MB. Do hypnozoites cause relapse in malaria? Trends Parasitol. 2015;31:239-45.

17. Huldén L, Huldén L, Heliövaara K. Natural relapses in vivax malaria induced by Anopheles mosquitoes. Malar J. 2008;7:64.

18. Ratcliff A, Siswantoro H, Kenangalem E, Maristela R, Wuwung RM, Laihad $\mathrm{F}$, et al. Two fixed-dose artemisinin combinations for drug-resistant Falciparum and vivax malaria in Papua, Indonesia: an open-label randomised comparison. Lancet. 2007;369:757-65.

19. Hasugian AR, Purba HLE, Kenangalem E, Wuwung RM, Ebsworth EP, Maristela R, et al. Dihydroartemisinin-piperaquine versus artesunateamodiaquine: superior efficacy and posttreatment prophylaxis against multidrug-resistant Plasmodium falciparum and Plasmodium vivax malaria. Clin Infect Dis. 2007;44:1067-74.

20. Price RN, Tjitra E, Guerra CA, Yeung S, White NJ, Anstey NM. Vivax malaria: neglected and not benign. Am J Trop Med Hyg. 2007;77(Suppl 6):79-87.

21. Awab GR, Pukrittayakamee S, Imwong M, Dondorp AM, Woodrow CJ, Lee SJ, et al. Dihydroartemisinin-piperaquine versus chloroquine to treat vivax malaria in Afghanistan: an open randomized, non-inferiority, trial. Malar J. 2010;9:105.

22. Lacerda MV, Mourão MP, Alexandre MA, Siqueira AM, Magalhães BM, Martinez-Espinosa FE, et al. Understanding the clinical spectrum of complicated Plasmodium vivax malaria: a systematic review on the contributions of the Brazilian literature. Malar J. 2012;11:12.

23. Lacerda MV, Mourão MP, Coelho HC, Santos JB. Thrombocytopenia in malaria: who cares? Mem Inst Oswaldo Cruz. 2011;106(Suppl 1):52-63.

24. Alexandre MA, Ferreira CO, Siqueira AM, Magalhães BL, Mourão MP, Lacerda MV, et al. Severe Plasmodium vivax malaria, Brazilian Amazon. Emerg Infect Dis. 2010;16:1611-4

25. Siqueira AM, Lacerda MV, Magalhães BM, Mourão MP, Melo GC, Alexandre MA, et al. Characterization of Plasmodium vivax-associated admissions to reference hospitals in Brazil and India. BMC Med. 2015;13:57.

26. Ketema T, Bacha K. Plasmodium vivax associated severe malaria complications among children in some malaria endemic areas of Ethiopia. BMC Public Health. 2013;13:637.

27. Limaye CS, Londhey VA, Nabar ST. The study of complications of vivax malaria in comparison with falciparum malaria in Mumbai. J Assoc Physicians India. 2012;60:15-8.

28. Schofield L, Grau GE. Immunological processes in malaria pathogenesis. Nat Rev Immunol. 2005;5:722-35.

29. Couper KN, Blount DG, Riley EM. IL-10: the master regulator of immunity to infection. J Immunol. 2008;180:5771-7.

30. Langhorne J, Ndungu FM, Sponaas AM, Marsh K. Immunity to malaria: more questions than answers. Nat Immunol. 2008;9:725-32.

31. Claser C, Malleret B, Gun SY, Wong AY, Chang ZW, Teo P, et al. CD8+ T cells and IFN- $\gamma$ mediate the time-dependent accumulation of infected red blood cells in deep organs during experimental cerebral malaria. PLoS ONE. 2011;6:e18720.

32. Belnoue E, Kayibanda M, Vigario AM, Deschemin JC, van Rooijen N, Viguier M, et al. On the pathogenic role of brain-sequestered alphabeta CD8+ T cells in experimental cerebral malaria. J Immunol. 2002;169:6369-75.

33. Engwerda CR, Mynott TL, Sawhney S, De Souza JB, Bickle QD, Kaye PM Locally up-regulated lymphotoxin alpha, not systemic tumor necrosis factor alpha, is the principle mediator of murine cerebral malaria. J Exp Med. 2002;195:1371-7.

34. Medina TS, Costa SP, Oliveira MD, Ventura AM, Souza JM, Gomes TF, et al. Increased interleukin-10 and interferon- $\gamma$ levels in Plasmodium vivax malaria suggest a reciprocal regulation which is not altered by IL-10 gene promoter polymorphism. Malar J. 2011;10:264.
35. Mendonça VR, Queiroz AT, Lopes FM, Andrade BB, Barral-Netto M. Networking the host immune response in Plasmodium vivax malaria. Malar J. 2013;12:69.

36. Greenwood BM, Bradley-Moore A, Bryceson AD, Palit A. Immunosuppression in children with malaria. Lancet. 1972;299:169-72.

37. Williamson WA, Greenwood BM. Impairment of the immune response to vaccination after acute malaria. Lancet. 1978:311:1328-9.

38. Mabey DC, Brown A, Greenwood BM. Plasmodium falciparum malaria and Salmonella infections in Gambian children. J Infect Dis. 1987;155:1319-21.

39. Goonewardene R, Carter R, Gamage CP, Del Giudice G, David PH, Howie S, et al. Human T cell proliferative responses to Plasmodium vivax antigens: evidence of immunosuppression following prolonged exposure to endemic malaria. Eur J Immunol. 1990;20:1387-91.

40. Cook IF. Herpes zoster in children following malaria. J Trop Med Hyg. 1985:88:261-4.

41. Walther $\mathrm{M}$, Tongren JE, Andrews $\mathrm{L}$, Korbel $\mathrm{D}$, King $\mathrm{E}$, Fletcher $\mathrm{H}$, et al. Upregulation of TGF- $\beta$, FOXP3, and CD4 + CD25+ regulatory T cells correlates with more rapid parasite growth in human malaria infection. Immunity. 2005;23:287-96.

42. Belkaid $Y$, Tarbell K. Regulatory T cells in the control of host-microorganism interactions. Annu Rev Immunol. 2009;27:551-89.

43. Riley EM, Wahl S, Perkins DJ, Schofield L. Regulating immunity to malaria. Parasite Immunol. 2006;28:35-49.

44. Nie CQ, Bernard NJ, Schofield L, Hansen DS. CD4 + CD25+ regulatory T cells suppress CD4+ T-cell function and inhibit the development of Plasmodium berghei-specific TH1 responses involved in cerebral malaria pathogenesis. Infect Immun. 2007;75:2275-82.

45. Imwong M, Snounou G, Pukrittayakamee S, Tanomsing N, Kim JR, Nandy $\mathrm{A}$, et al. Relapses of Plasmodium vivax infection usually result from activation of heterologous hypnozoites. J Infect Dis. 2007;195:927-33.

46. Mueller I, Galinski MR, Baird JK, Carlton JM, Kochar DK, Alonso PL, et al. Key gaps in the knowledge of Plasmodium vivax, a neglected human malaria parasite. Lancet Infect Dis. 2009;9:555-66.

47. White NJ. The assessment of antimalarial drug efficacy. Trends Parasitol. 2002;18:458-64.

48. Malaria's treatment in Brazil practical guide. Guia prático de tratamento da malária no Brasil/Ministério da Saúde, Secretaria de Vigilância em Saúde, Departamento de Vigilância Epidemiológica.-Brasília: Ministério da Saúde. 2010. 36. http://bvsms.saude.gov.br/bvs/publicacoes/guia_ pratico_malaria.pdf.

49. Versiani FG, Almeida ME, Melo GC, Versiani FO, Orlandi PP, Mariúba LA, et al. High levels of IgG3 anti ICB2-5 in Plasmodium vivax-infected individuals who did not develop symptoms. Malar J. 2013;12:294.

50. Snounou G, Singh B. Nested PCR analysis of Plasmodium parasites. Methods Mol Med. 2002;72:189-203.

51. Rodríguez-Morales AJ, Sánchez E, Arria M, Vargas M, Piccolo C, Colina R, et al. White blood cell counts in Plasmodium vivax malaria. J Infect Dis. 2005:192:1675-6.

52. Safeukui I, Gomez ND, Adelani AA, Burte F, Afolabi NK, Akondy R, et al. Malaria induces anemia through CD8+T cell-dependent parasite. MBio. 2015;6:e02493.

53. Mahanta A, Kar SK, Kakati S, Baruah S. Heightened inflammation in severe malaria is associated with decreased IL-10 expression levels and neutrophils. Innate Immun. 2015;21:546-52.

54. Gonçalves RM, Lima NF, Ferreira MU. Parasite virulence, co-infections and cytokine balance in malaria. Pathog Glob Health. 2014;108:173-8.

55. Kassa D, Petros B, Mesele T, Hailu E, Wolday D. Characterization of peripheral blood lymphocyte subsets in patients with acute Plasmodium falciparum and P. vivax malaria infections at Wonji Sugar Estate. Clin Vaccine Immunol. 2006;13:376-9.

56. Worku S, Björkman A, Troye-Blomberg M, Jemaneh L, Färnert A, Christensson B. Lymphocyte activation and subset redistribution in the peripheral blood in acute malaria illness: distinct gammadelta+ T cell patterns in Plasmodium falciparum and P. vivax infections. Clin Exp Immunol. 1997;108:34-41.

57. Lisse IM, Aaby P, Whittle H, Knudsen K. A community study of T lymphocyte subsets and malaria parasitaemia. Trans R Soc Trop Med Hyg. 1994:88:709-10. 
58. Jangpatarapongsa K, Xia H, Fang Q, Hu K, Yuan Y, Peng M, et al. Immunity to malaria in Plasmodium vivax infection: a study in Central China. PLoS ONE. 2012;7:e45971.

59. Wickramasinghe SN, Abdalla SH. Blood and bone marrow changes in malaria. Baillieres Best Pract. Res Clin Haematol. 2000;13:277-99.

60. Hviid L, Kurtzhals JA, Goka BQ, Oliver-Commey JO, Nkrumah FK, Theander TG. Rapid reemergence of T cells into peripheral circulation following treatment of severe and uncomplicated Plasmodium falciparum malaria. Infect Immun. 1997;65:4090-3.

61. Ho M, Webster HK. T cell responses in acute falciparum malaria. Immunol Lett. 1990:25:135-8.

62. Greenwood BM, Oduloju AJ, Stratton D. Lymphocyte changes in acute malaria. Trans R Soc Trop Med Hyg. 1977;71:408-10.

63. Hojo-Souza NS, Pereira DB, Passos LS, Gazzinelli-Guimarães PH, Cardoso MS, Tada MS, et al. Phenotypic profiling of CD8(+) T cells during Plasmodium vivax blood-stage infection. BMC Infect Dis. 2015;15:35.

64. Borges QI, Fontes CJ, Damazo AS. Analysis of lymphocytes in patients with Plasmodium vivax malaria and its relation to the annexin-A1 and IL-10. Malar J. 2013;12:455.

65. Chuangchaiya S, Jangpatarapongsa K, Chootong P, Sirichaisinthop J, Sattabongkot J, Pattanapanyasat K, et al. Immune response to Plasmodium vivax has a potential to reduce malaria severity. Clin Exp Immunol. 2010;160:233-9.

66. Riccio EK, Júnior IN, Riccio LR, das Graças Alecrim M, Corte-Real S, Morgado $\mathrm{M}$, et al. Malaria associated apoptosis is not significantly correlated with either parasitemia or the number of previous malaria attacks. Parasitol Res. 2003:90:9-18.

67. Baldé AT, Sarthou JL, Roussilhon C. Acute Plasmodium falciparum infection is associated with increased percentages of apoptotic cells. Immunol Lett. 1995;46:59-62.

68. Jangpatarapongsa K, Sirichaisinthop J, Sattabongkot J, Cui L, Montgomery SM, Looareesuwan S, et al. Memory T cells protect against Plasmodium vivax infection. Microbes Infect. 2006:8:680-6.

69. Gonçalves RM, Scopel KK, Bastos MS, Ferreira MU. Cytokine balance in human malaria: does Plasmodium vivax elicit more inflammatory responses than Plasmodium falciparum? PLoS ONE. 2012;7:e44394.

70. Coelho HC, Lopes SC, Pimentel JP, Nogueira PA, Costa FT, Siqueira AM, et al. Thrombocytopenia in Plasmodium vivax malaria is related to platelets phagocytosis. PLoS ONE. 2013;8:e63410.

71. Baptista JL, Vanham G, Wéry M, Van Marck E. Cytokine levels during mild and cerebral falciparum malaria in children living in a mesoendemic area. Trop Med Int Health. 1997;2:673-9.

72. Guimarães da Costa A, do Valle Antonelli LR, Augusto Carvalho Costa P, Paulo Diniz Pimentel J, Garcia NP. Monteiro Tarragô A, et al. The robust and modulated biomarker network elicited by the Plasmodium vivax infection is mainly mediated by the IL-6/L-10 axis and is associated with the parasite load. J Immunol Res. 2014;2014:318250.

73. Karunaweera ND, Grau GE, Gamage P, Carter R, Mendis KN. Dynamics of fever and serum levels of tumor necrosis factor are closely associated during clinical paroxysms in Plasmodium vivax malaria. Proc Natl Acad Sci USA. 1992:89:3200-3.
74. Akanmori BD, Kurtzhals JA, Goka BQ, Adabayeri V, Ofori MF, Nkrumah FK, et al. Distinct patterns of cytokine regulation in discrete clinical forms of Plasmodium falciparum malaria. Eur Cytokine Netw. 2000;11:113-8.

75. Rodrigues-da-Silva RN, Lima-Junior JC, Fonseca BP, Antas PR, Baldez A, Storer $\mathrm{FL}$, et al. Alterations in cytokines and haematological parameters during the acute and convalescent phases of Plasmodium falciparum and Plasmodium vivax infections. Mem Inst Oswaldo Cruz. 2014;109:154-62.

76. Hansen DS, Schofield L. Natural regulatory T cells in malaria: host or parasite allies? PLoS Pathog. 2010;6:e1000771.

77. Kwak YG, Lee HK, Kim M, Um TH, Cho CR. Clinical characteristics of vivax malaria and analysis of recurred patients. Infect Chemother. 2013;45:69-75

78. Pedro RS, Guaraldo L, Campos DP, Costa AP, Daniel-Ribeiro CT, Brasil P. Plasmodium vivax malaria relapses at a travel medicine centre in Rio de Janeiro, a non-endemic area in Brazil. Malar J. 2012;11:245.

79. Takem EN, Roca A, Cunnington A. The association between malaria and non-typhoid Salmonella bacteraemia in children in sub-Saharan Africa: a literature review. Malar J. 2014;13:400.

80. Bronzan RN, Taylor TE, Mwenechanya J, Tembo M, Kayira K, Bwanaisa L, et al. Bacteremia in Malawian children with severe malaria: prevalence, etiology, HIV coinfection, and outcome. J Infect Dis. 2007;195:895-904.

81. Were T, Davenport GC, Hittner JB, Ouma C, Vulule JM, Ong'echa JM, et al Bacteremia in Kenyan children presenting with malaria. J Clin Microbiol. 2011:49:671-6.

82. Freitas do Rosario AP, Langhorne J. T cell-derived IL-10 and its impact on the regulation of host responses during malaria. Int J Parasitol. 2012:42:549-55.

83. Silva AL, Lacerda MV, Fujiwara RT, Bueno LL, Braga ÉM. Plasmodium vivax infection induces expansion of activated naïve/memory Tcells and differentiation into a central memory profile. Microbes Infect. 2013;15:837-43.

84. Wipasa J, Okell L, Sakkhachornphop S, Suphavilai C, Chawansuntati K, Liewsaree W, et al. Short-lived IFN- $\gamma$ effector responses, but long-lived IL-10 memory responses, to malaria in an area of low malaria endemicity. PLoS Pathog. 2011;7:e1001281.

85. Freitas do Rosario AP, Lamb T, Spence P, Stephens R, Lang A, Roers A, et al. IL-27 promotes IL-10 production by effector Th1 CD4+T cells: a critical mechanism for protection from severe immunopathology during malaria infection. J Immunol. 2012;188:1178-90.

86. Fiorentino DF, Zlotnik A, Mosmann TR, Howard M, O'Garra A. IL-10 inhibits cytokine production by activated macrophages. J Immunol. 1991;147:3815-22.

87. Mosmann TR, Moore KW. The role of $\mathrm{IL}-10$ in crossregulation of TH1 and TH2 responses. Immunol Today. 1991;12:A49-53.

\section{Submit your next manuscript to BioMed Central and we will help you at every step:}

- We accept pre-submission inquiries

- Our selector tool helps you to find the most relevant journal

- We provide round the clock customer support

- Convenient online submission

- Thorough peer review

- Inclusion in PubMed and all major indexing services

- Maximum visibility for your research

Submit your manuscript at www.biomedcentral.com/submit 